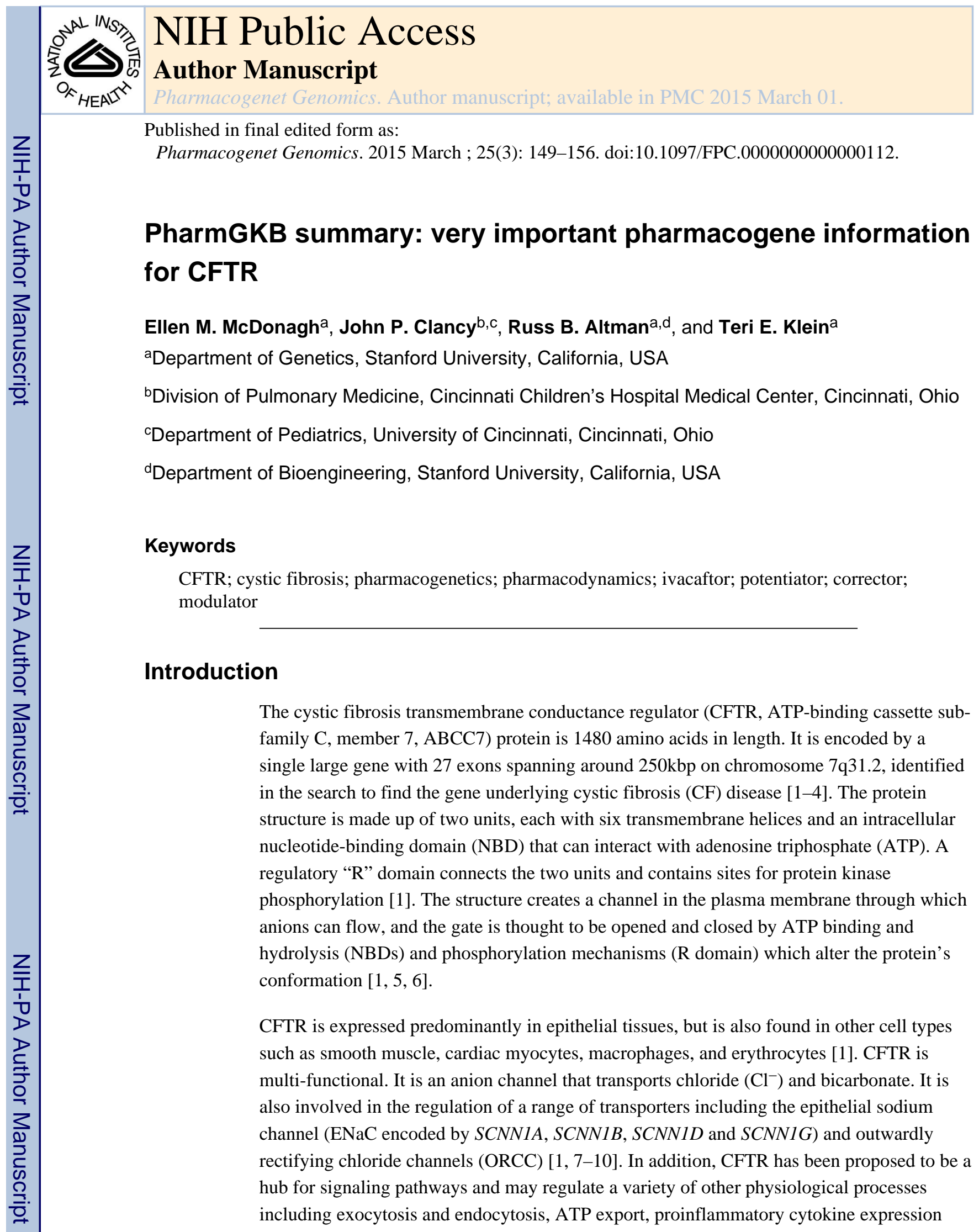

Correspondence to Dr Teri E. Klein, PhD, Department of Genetics, Stanford School of Medicine, Shriram Center, 443 Via Ortega, Room 213, Stanford, CA 94305-4125, USA. Tel: +1 650736 0156; fax: +1 650725 3863; teri.klein@ stanford.edu. 
and intracellular $\mathrm{pH}[1,10]$. Defective CFTR therefore results in widespread cellular homeostasis dysfunction [10].

$\mathrm{CF}$ is an autosomal recessive disease resulting from a defect-causing variant on each CFTR allele. More than 1800 variants in the CFTR gene have been reported [11]. Despite a large collection of variants, there is a gap in our knowledge regarding which cause CF disease. To address this, the Clinical and Functional Translation of CFTR project was established to collect information regarding the functional consequences and resulting phenotypes associated with $C F T R$ variants $[12,13]$. Data for 39,696 subjects from 25 CF patient registries or specialty clinics were collected for the database, and an initial set of 159 CFTR variants (those with a frequency of $\geq 0.01 \%$ in the CFTR2 database) was evaluated for whether they cause CF disease by both clinical phenotype and functional analysis [12]. A variant was defined clinically as causing CF if mean sweat chloride concentration was $\checkmark 60 \mathrm{mM}$ for at least three individuals with the variant or $>90 \mathrm{mM}$ if only 2 individuals with the variant were available; 140 variants met the clinical criteria to be CF-causing. The variants were sorted by their predicted functional effect, and 77 were investigated further using in vitro assays appropriate to the genetic variant ( $<10 \%$ of wild-type CFTR function was considered disease-causing); 133 variants were deemed CF-causing by functional criteria. In total, 127 variants met both the clinical and functional criteria, and were defined as CF-causing. Penetrance analysis in fathers with $\mathrm{CF}$ children was carried out on the variants that did not meet both/either criteria and 12 variants were deemed non-CF causing, with the remaining 20 variants indeterminate $[12,13]$.

$\mathrm{CF}$ is a disease that predominantly affects the lungs but has a diverse array of phenotypes due to the expression of CFTR in different tissues, its wide-ranging physiological role, and its involvement in many signaling pathways $[1,7,10]$. Progressive lung disease, pancreatic dysfunction, infertility in males and elevated sweat electrolytes characterize a "classical" CF diagnosis [14]. CF is also associated with a reduced life expectancy (early adulthood) and an increased risk of cancer $[1,10]$. There is, however, wide variability in clinical presentation, severity and the rate of disease progression between patients, which can be influenced by the underlying CFTR genotype as well as other genetic modifiers and environmental factors [1, $7,10,14-17]$. The incidence of CF is thought to be around 70,000 cases worldwide [18], though it may be largely under-diagnosed in parts of Asia, Africa and Latin America [14, 19]. Genetic testing is now a routine part of CF diagnosis in many countries. A recommended panel for genetic screening for determining prenatal and preconception carrier status of CF in the US includes 23 CFTR variants, designed to cover variants with a frequency of at least $0.1 \%$ in CF patients that are associated with classical CF disease, for a pan-ethnic US population [20-22]. The WHO recommends sequencing of the complete CFTR gene in CF patients from populations where CF is likely under-diagnosed in order to establish panels of population-specific variants known to cause disease [14].

\section{Pharmacogenetics (PGx)}

Traditionally, drugs used in the treatment of CF have focused on ameliorating symptoms, fighting infection, thinning mucus and dampening inflammation, rather than directly targeting the cause: variants in the CFTR gene. Gene therapy techniques aimed at replacing 
defective CFTR with a functional version of the gene have been extensively researched and remain a hope for curing $\mathrm{CF}$ after the discovery of the underlying disease cause. Unfortunately, gene therapy has encountered several barriers that have kept it from becoming a treatment option for $\mathrm{CF}$ [23], though the results of an ongoing clinical trial are eagerly awaited [24, 25]. Drugs that are designed to correct specific defects of the CFTR protein are being developed as novel therapies for CF; these are termed "modulators" of CFTR. Repurposing of drugs for CF treatment due to their mechanism of action as a CFTR modulator is also a potential therapeutic option (see [1]). This summary focuses on pharmacogenetics, and thus therapies that directly target defects resulting from variants in the CFTR gene. An interactive version of this summary, with links to further study information, is available online at https://www.pharmgkb.org/vip/PA109.

CFTR variants can be grouped into 6 classes depending on the resulting effect on the protein, and each could potentially be targeted by a treatment strategy aimed at the underlying defect: see Table 1. Modulator molecules also have the benefit of being administered orally, thus potentially targeting multiple organs and cell types affected by a defect in CFTR [26]. Included in the spectrum of modulators are "correctors" and "potentiators". Correctors are molecules that 'correct' the misfolding/trafficking of defective CFTR protein to increase expression at the cell surface, whereas potentiators enhance the channel opening of the defective protein within the cell membrane [27].

Currently, the most commonly accepted efficacy endpoints for late phase clinical trials in $\mathrm{CF}$ include lung function (forced expiratory volume in one second), pulmonary exacerbation rates, growth/body mass index, and patient reported outcomes [28]. Additional outcome measures are in development and may serve to accelerate CFTR modulator development in $\mathrm{CF}$, including multiple breath washout (lung clearance index), pulmonary imaging (including computed tomography and mucociliary clearance), cardiopulmonary exercise testing, gastrointenstinal $\mathrm{pH}$, a variety of sputum biomarkers and changes in microbiome [29-32]. Change in mean sweat chloride concentration is also currently used as a biomarker of CF; however, there is controversy regarding sweat chloride as a predictive biomarker for improvement in lung function [33-35]. Guidelines recommending particular biomarkers for CF therapy trials have been published [36]. Modulators may have different effects in different tissues/cells which should be taken into account when personalizing CF treatment for an individual patient [26].

\section{Important PGx variants}

\section{G551D-CFTR}

Variant mapping information: c. 1652G>A (NM_000492.3), Gly551Asp (NP_000483.3), rs75527207.

This variant is a single nucleotide polymorphism (SNP) at position c. $1652 \mathrm{G}>\mathrm{A}$ that causes a Gly to Asp change at amino acid position 551. The resulting G551D-CFTR protein belongs to the class III group of CFTR variants: it is expressed at the plasma membrane but is defective in ATP hydrolysis and channel gating (Table 1) [1, 5]. In homozygotes, or when in combination with another nonfunctional disease-causing allele, it is associated with causing 
CF characterized by a pancreatic insufficiency phenotype [13]. It is one of the variants in a recommended panel for newborn screening of CF by the American College of Medical Genetics [21]. Global allele frequencies are calculated at 0.02 in Caucasian, 0.025 in African, 0.004 in Mexican, 0.003 in South American, 0.002 in Mediterranean and 0.001 in Middle Eastern CF patients (see CPIC CFTR-ivacaftor guideline supplement for individual references) [37].

\section{Pharmacogenetics}

Ivacaftor (VX-770, kalydeco) is a potentiator and is the first FDA-approved therapeutic developed to target a specific $C F T R$ defect. It was originally indicated in CF patients 6 years and older who have at least one G551D variant (rs75527207 genotype AA or GA) [37]. Ivacaftor targets the gating defect of G551D-CFTR to enhance activity; in vitro studies show it enhances open channel probability and increases chloride transport of G551D-CFTR expressing cells [38-43]. It has also been shown to enhance cilia beating and decrease sodium absorption in bronchial epithelial cells from a patient with the G551D/F508del genotype [39]. It may also have anti-bacterial properties [44]. In vivo, clinical trials or case reports of CF patients with at least one copy of the G551D variant demonstrate improved lung function with ivacaftor treatment [28-30, 41, 45-47]. The response in patients with severe CF with at least one copy of the $G 551 D$ variant seems variable, and a case report suggests that the drug may be more effective in patients homozygous for G551D-CFTR [4649]. Ivacaftor may delay or prevent the development of diabetes or even resolve diabetes in CF patients, though more investigation into these effects is needed [50, 51]. As ivacaftor is such a new therapeutic, it is not currently possible to assess its long-term efficacy or harmbenefit balance, discussed further in [52], though a recent study provides results up to 144 weeks of treatment [53].

The indication section of the FDA-approved ivacaftor drug label was amended in February 2014 to include a further eight CFTR variants (corresponds to a total of ten genetic variants, listed in Table 2) [54]. All variants show defects in gating in vitro, as measured by decreased open channel probability and chloride transport, compared to wild-type CFTR [38]. The FDA-approved drug label refers to a clinical trial carried out in 39 patients who had at least one of these variants. Clinical trials of ivacaftor in patients with one of a number of nonG551D CFTR gating variants are currently underway or have been completed [55, 56], and results from the phase 3 KONNECTION study were recently announced in press releases and at the $37^{\text {th }}$ European CF Society conference (June 2014) [57]. However, to our knowledge, no published peer-reviewed clinical data regarding these trials are available to date.

Ivacaftor alone or in combination with other drugs may also be effective in patients with CFTR variants other than the gating defects listed in Table 2, as has been shown in vitro [43]. A clinical trial in patients with the $R 117 H$ (c.350G $>\mathrm{A}$, rs78655421) variant has been completed (KONDUCT study), results from this trial and a rollover study of patients who completed this trial have been announced in press releases and at the $37^{\text {th }}$ European CF Society conference (June 2014) but to our knowledge are not currently published in peerreviewed literature [58]. According to press releases, Vertex plans to submit a supplemental 
New Drug Application in the USA and a marketing authorization application variation in Europe for patients 18 years and older who have the $R 117 \mathrm{H}$ variant.

\section{F508del-CFTR}

Variant mapping information: c.1521_1523delCTT and c. 1520_1522delTCT (NM_000492.3), Phe508del (NP_000483.3), rs113993960 and rs199826652, respectively. Also referred to as $\Delta$-F508, F508del.

This variant was originally identified in 1989 after comparison of cDNA sequences from patients with CF and unaffected individuals [59]. It currently has two dbSNP reference sequence IDs (rsIDs) that represent the same variant, likely due to differences in how the DNA sequence can be read. Rs113993960 refers to a CTT deletion at cDNA position c. 1521_1523delCTT (NM_000492.3). This is the cDNA sequence referred to by the Cystic Fibrosis Mutation Database [11] and is flagged by the ClinVar database as having a pathogenic allele [60]. Rs199826652 refers to a TCT deletion (cDNA sequence 1520_1522) and is more likely to be called in sequencing analysis due to the left justification of indels - a minor allele count of 0.006 is provided from 1000 genomes [61].

Whichever way the DNA sequence is read, the 3 basepair deletion ultimately results in a loss of a phenylalanine amino acid at position 508 in the NBD of the protein [59]. It is a class II variant: F508del-CFTR gets trapped in the endoplasmic reticulum where it is prematurely degraded and largely fails to traffic to the plasma membrane (Table 1$)[1,10$, 62]. It is associated with causing CF (in homozygotes or when in combination with another disease-causing allele) and is also associated with pancreatic insufficiency [13]. In most populations, this is the most frequent CF-causing CFTR variant, although allele frequencies vary in different population groups of CF patients, from $100 \%$ in an isolated Danish population to around 20\% in Turkey [14]. In Ashkenazis from Israel the W1282X-CFTR (c. $3846 \mathrm{G}>\mathrm{A}$, rs77010898) variant is more common than F508del-CFTR [14]. Global frequencies are estimated at 0.66 in Caucasian, 0.48 in Mediterranean, 0.44 in Mexican, 0.42 in African, 0.39 in South American, and 0.21 in Middle Eastern CF patients (see CPIC CFTR-ivacaftor guideline supplement for individual references) [37].

\section{Pharmacogenetics}

Numerous different correctors targeting F508del-CFTR defective function are being identified, developed and investigated (Table 1) [1, 63-66]. Lumacaftor (VX-809) is an investigational drug currently undergoing clinical trials that acts as a corrector [67-69]. In vitro it is thought to improve F508del-CFTR maturation and chloride transport by suppressing the folding defect and increasing exit from the ER, though F508del-CFTR remains thermodynamically unstable [70-72]. Human bronchial epithelial cells from F508del-CFTR homozygous patients treated with lumacaftor were reported to have enhanced CFTR maturation and chloride secretion in vitro [70]. In a clinical trial to assess safety in CF patients homozygous for F508del-CFTR, sweat chloride levels were significantly decreased in patients given $100 \mathrm{mg} /$ day or $200 \mathrm{mg} /$ day lumacaftor over 28 days compared to placebo-treated patients. No improvements in other clinical parameters were observed; however, the study was not powered to determine differences in these 
measurements [73]. Clinical trials of other correctors have also failed to show clinical efficacy in CF patients homozygous for F508del-CFTR (Table 1 footnote) [74]. Due to the complex nature of the F508del-CFTR defect, it is likely that combinations of correctors, and/or correctors in combination with a potentiator will be necessary to achieve clinical efficacy in these patients $[74,75]$. Compounds with dual corrector and potentiator activities have been reported in vitro and may have therapeutic potential $[26,76]$.

Currently, ivacaftor monotherapy is not recommended in CF patients homozygous for the F508del-CFTR variant (rs113993960 or rs199826652 genotype del/del) [37, 54]. This may be due to ivacaftor's mechanism of action as a potentiator (Table 1). Since F508del-CFTR is a class II variant that results in minimal cell surface protein expression, ivacaftor would likely be ineffective in these patients. Indeed, a study examining the safety of ivacaftor in CF patients homozygous for the F508del-CFTR variant saw no differences in efficacy compared to placebo; however, was not powered to examine efficacy [77]. In vitro studies suggest that if expression to the cell surface is restored (by temperature treatment, a correcting mutation or a cell-free system), ivacaftor can potentiate F508del-CFTR activity [38-40, 43, 78-80]. Therefore, the hypothesis is that combination therapy with a potentiator such as ivacaftor and a corrector may be effective in these patients. In vitro, ivacaftor addition potentiates lumacaftor-corrected F508del-CFTR [70, 80]. Results from a doubleblind, placebo-controlled phase 2 study in patients either homozygous or heterozygous for F508del-CFTR were recently published (NCT01225211) [81]; results for the clinical efficacy of the combination compared to placebo were less than the effect of ivacaftor monotherapy that has been demonstrated in patients with G551D-CFTR. The one treatment arm that showed significant differences in absolute change in percent predicted $\mathrm{FEV}_{1}$ compared to placebo at treatment completion, was the group of patients homozygous for F508del-CFTR treated with a monotherapy of $600 \mathrm{mg}$ lumacaftor once per day for 28 days, followed by combination with $250 \mathrm{mg}$ ivacaftor twice a day for an additional 28 days. In this treatment group, the occurrence of dyspnoea and chest tightness during both monotherapy and combination therapy periods, compared to no occurrences in the placebo group, is of concern (at least one patient in each treatment arm withdrew due to an adverse event starting on day 1 of lumacaftor monotherapy). In this cohort, the placebo group was a mix of F508del-CFTR homozygotes and heterozygotes. This is therefore not reflective of the wholly homozygous or heterozygous patient treatment arms within this cohort that were compared against this mixed placebo group. Comparing treatment efficacy in patients with varying genotypes can introduce confounders that could influence study outcomes. Another issue was the lack of correlation between $\mathrm{FEV}_{1}$ responses and sweat chloride responses observed, limiting the use of sweat chloride to predict F508del-CFTR restoration.

Other registered clinical trials in $F 508 \mathrm{del}$ homozygous patients investigating a combinational treatment of ivacaftor with lumacaftor are currently ongoing [67-69]. Results at 24 weeks of the TRAFFIC and TRANSPORT Phase 3 studies were recently announced by press release, though to our knowledge are not yet published in peer-reviewed literature. Chronic treatment of primary epithelial cells homozygous for F508del-CFTR or F508del$C F T R$-expressing cell lines with ivacaftor or several other potentiators has recently been 
reported to reduce stability and increase turnover of lumacaftor-corrected F508del-CFTR, and thus may have implications for long-term treatment [26, 82, 83].

\section{Conclusion}

Cystic fibrosis (CF) is a life-shortening autosomal recessive disease, caused by variants in the $C F T R$ gene, with considerable treatment burden and morbidity. Strategies to modify defects in CFTR are being developed in a potential new wave of CF therapies. The first to be approved by the FDA, a potentiator named ivacaftor, targets CFTR protein variants defective in gating and is indicated in patients who carry certain underlying CFTR genetic variants. Correctors and combinations of modulators are currently in clinical trials in patients with the commonly found F508del-CFTR variant. Future hopes are a panel of therapies that can be tailored for a patient's underlying genetic variants for a more effective treatment strategy to minimize symptoms and extend longevity.

\section{Acknowledgements}

This work is supported by the NIH/NIGMS (R24 GM61374).

Conflicts of Interest

RBA and TEK are stockholders in Personalis Inc. JPC has received grant support from Vertex Pharmaceuticals to conduct clinical trials with CFTR modulators in CF patients. He has received honoraria from Vertex Pharmaceuticals for educational presentations regarding the appropriate use of ivacaftor in CF patients.

\section{References}

1. Lubamba B, Dhooghe B, Noel S, Leal T. Cystic fibrosis: insight into CFTR pathophysiology and pharmacotherapy. Clin Biochem. 2012; 45:1132-1144. [PubMed: 22698459]

2. Zielenski J, Rozmahel R, Bozon D, Kerem B, Grzelczak Z, Riordan JR, Rommens J, Tsui LC. Genomic DNA sequence of the cystic fibrosis transmembrane conductance regulator (CFTR) gene. Genomics. 1991; 10:214-228. [PubMed: 1710598]

3. Rommens JM, Iannuzzi MC, Kerem B, Drumm ML, Melmer G, Dean M, Rozmahel R, Cole JL, Kennedy D, Hidaka N, et al. Identification of the cystic fibrosis gene: chromosome walking and jumping. Science. 1989; 245:1059-1065. [PubMed: 2772657]

4. Collins FS. Cystic fibrosis: molecular biology and therapeutic implications. Science. 1992; 256:774-779. [PubMed: 1375392]

5. Li C, Ramjeesingh M, Wang W, Garami E, Hewryk M, Lee D, Rommens JM, Galley K, Bear CE. ATPase activity of the cystic fibrosis transmembrane conductance regulator. J Biol Chem. 1996; 271:28463-28468. [PubMed: 8910473]

6. Wang Y, Wrennall JA, Cai Z, Li H, Sheppard DN. Understanding how cystic fibrosis mutations disrupt CFTR function: From single molecules to animal models. Int J Biochem Cell Biol. 2014

7. Kotha K, Clancy JP. Ivacaftor treatment of cystic fibrosis patients with the G551D mutation: a review of the evidence. Ther Adv Respir Dis. 2013; 7:288-296. [PubMed: 24004658]

8. Gabriel SE, Clarke LL, Boucher RC, Stutts MJ. CFTR and outward rectifying chloride channels are distinct proteins with a regulatory relationship. Nature. 1993; 363:263-268. [PubMed: 7683773]

9. Schwiebert EM, Flotte T, Cutting GR, Guggino WB. Both CFTR and outwardly rectifying chloride channels contribute to cAMP-stimulated whole cell chloride currents. Am J Physiol. 1994; 266:C1464-C1477. [PubMed: 7515570]

10. Kunzelmann K, Mehta A. CFTR: a hub for kinases and crosstalk of cAMP and Ca2+ FEBS J. 2013; 280:4417-4429. [PubMed: 23895508] 
11. Cystic Fibrosis Mutation Database. [accessed 22nd April 2014] http://www.genet.sickkids.on.ca/ $\mathrm{cftr} /$ Home.html

12. Sosnay PR, Siklosi KR, Van Goor F, Kaniecki K, Yu H, Sharma N, Ramalho AS, Amaral MD, Dorfman R, Zielenski J, et al. Defining the disease liability of variants in the cystic fibrosis transmembrane conductance regulator gene. Nat Genet. 2013; 45:1160-1167. [PubMed: 23974870]

13. The Clinical and Functional TRanslation of CFTR (CFTR2). [accessed 22nd April 2014] available at http://cftr2.org

14. The molecular genetic epidemiology of cystic fibrosis. Report of a joint meeting of WHO/ECFTN/ ICF(M)A/ECFS. 2004

15. Kerem E, Corey M, Kerem BS, Rommens J, Markiewicz D, Levison H, Tsui LC, Durie P. The relation between genotype and phenotype in cystic fibrosis--analysis of the most common mutation (delta F508). N Engl J Med. 1990; 323:1517-1522. [PubMed: 2233932]

16. Li W, Soave D, Miller MR, Keenan K, Lin F, Gong J, Chiang T, Stephenson AL, Durie P, Rommens J, et al. Unraveling the complex genetic model for cystic fibrosis: pleiotropic effects of modifier genes on early cystic fibrosis-related morbidities. Hum Genet. 2013

17. Wright FA, Strug LJ, Doshi VK, Commander CW, Blackman SM, Sun L, Berthiaume Y, Cutler D, Cojocaru A, Collaco JM, et al. Genome-wide association and linkage identify modifier loci of lung disease severity in cystic fibrosis at 11p13 and 20q13.2. Nat Genet. 2011; 43:539-546. [PubMed: 21602797]

18. Cystic Fibrosis Foundation, Overview. [accessed 22nd April 2014] http://www.cff.org/AboutCF/

19. Girisha KM. CFTR Mutations in India: Need to do More. Indian Pediatr. 2014; 51:177-178. [PubMed: 24736905]

20. American College of O, Gynecologists Committee on G: ACOG Committee Opinion No. 486: Update on carrier screening for cystic fibrosis. Obstet Gynecol. 2011; 117:1028-1031. [PubMed: 21422883]

21. Watson MS, Cutting GR, Desnick RJ, Driscoll DA, Klinger K, Mennuti M, Palomaki GE, Popovich BW, Pratt VM, Rohlfs EM, et al. Cystic fibrosis population carrier screening: 2004 revision of American College of Medical Genetics mutation panel. Genet Med. 2004; 6:387-391. [PubMed: 15371902]

22. Langfelder-Schwind E, Karczeski B, Strecker MN, Redman J, Sugarman EA, Zaleski C, Brown T, Keiles S, Powers A, Ghate S, Darrah R. Molecular testing for cystic fibrosis carrier status practice guidelines: recommendations of the National Society of Genetic Counselors. J Genet Couns. 2014; 23:5-15. [PubMed: 24014130]

23. Lee TW, Southern KW. Topical cystic fibrosis transmembrane conductance regulator gene replacement for cystic fibrosis-related lung disease. Cochrane Database Syst Rev. 2013; 11:CD005599. [PubMed: 24282073]

24. ClinicalTrials.gov Identifier. NCT01621867 "Repeated Application of Gene Therapy in CF Patients”. Sponser: Imperial College London; URL: http://www.clinicaltrials.gov/ct2/show/ NCT01621867 [ongoing - accessed 22nd April 2014]

25. Armstrong DK, Cunningham S, Davies JC, Alton EW. Gene therapy in cystic fibrosis. Arch Dis Child. 2014; 99:465-468. [PubMed: 24464978]

26. Ikpa PT, Bijvelds MJ, de Jonge HR. Cystic fibrosis: Toward personalized therapies. Int J Biochem Cell Biol. 2014; 52C:192-200. [PubMed: 24561283]

27. Clancy JP, Jain M. Personalized medicine in cystic fibrosis: dawning of a new era. Am J Respir Crit Care Med. 2012; 186:593-597. [PubMed: 22723294]

28. Ramsey BW, Davies J, McElvaney NG, Tullis E, Bell SC, Drevinek P, Griese M, McKone EF, Wainwright CE, Konstan MW, et al. A CFTR potentiator in patients with cystic fibrosis and the G551D mutation. N Engl J Med. 2011; 365:1663-1672. [PubMed: 22047557]

29. Davies J, Sheridan H, Bell N, Cunningham S, Davis SD, Elborn JS, Milla CE, Starner TD, Weiner DJ, Lee PS, Ratjen F. Assessment of clinical response to ivacaftor with lung clearance index in cystic fibrosis patients with a G551D-CFTR mutation and preserved spirometry: a randomised controlled trial. Lancet Respir Med. 2013; 1:630-638. [PubMed: 24461666] 
30. Rowe SM, Heltshe SL, Gonska T, Donaldson SH, Borowitz D, Gelfond D, Sagel SD, Khan U, Mayer-Hamblett N, Van Dalfsen JM, et al. Clinical mechanism of the cystic fibrosis transmembrane conductance regulator potentiator ivacaftor in G551D-mediated cystic fibrosis. Am J Respir Crit Care Med. 2014; 190:175-184. [PubMed: 24927234]

31. Saynor ZL, Barker AR, Oades PJ, Williams CA. The Effect of Ivacaftor in Adolescents With Cystic Fibrosis (G551D Mutation): An Exercise Physiology Perspective. Pediatr Phys Ther. 2014; 26:454-461. [PubMed: 25251804]

32. Hayes D Jr, Long FR, McCoy KS, Sheikh SI. Improvement in Bronchiectasis on CT Imaging in a Pediatric Patient with Cystic Fibrosis on Ivacaftor Therapy. Respiration. 2014; 88:345. [PubMed: 25171465]

33. Barry PJ, Jones AM, Webb AK, Horsley AR. Sweat chloride is not a useful marker of clinical response to Ivacaftor. Thorax. 2013

34. Durmowicz AG, Witzmann KA, Rosebraugh CJ, Chowdhury BA. Change in sweat chloride as a clinical end point in cystic fibrosis clinical trials: the ivacaftor experience. Chest. 2013; 143:1418. [PubMed: 23276841]

35. Accurso FJ, Van Goor F, Zha J, Stone AJ, Dong Q, Ordonez CL, Rowe SM, Clancy JP, Konstan MW, Hoch HE, et al. Sweat chloride as a biomarker of CFTR activity: proof of concept and ivacaftor clinical trial data. J Cyst Fibros. 2014; 13:139-147. [PubMed: 24660233]

36. De Boeck K, Kent L, Davies J, Derichs N, Amaral M, Rowe SM, Middleton P, de Jonge H, Bronsveld I, Wilschanski M, et al. CFTR biomarkers: time for promotion to surrogate end-point. Eur Respir J. 2013; 41:203-216. [PubMed: 22878883]

37. Clancy JP, Johnson SG, Yee SW, McDonagh EM, Caudle KE, Klein TE, Cannavo M, Giacomini KM. Clinical Pharmacogenetics Implementation Consortium (CPIC) Guidelines for Ivacaftor Therapy in the Context of CFTR Genotype. Clin Pharmacol Ther. 2014

38. Yu H, Burton B, Huang CJ, Worley J, Cao D, Johnson JP Jr, Urrutia A, Joubran J, Seepersaud S, Sussky K, et al. Ivacaftor potentiation of multiple CFTR channels with gating mutations. J Cyst Fibros. 2012; 11:237-245. [PubMed: 22293084]

39. Van Goor F, Hadida S, Grootenhuis PD, Burton B, Cao D, Neuberger T, Turnbull A, Singh A, Joubran J, Hazlewood A, et al. Rescue of CF airway epithelial cell function in vitro by a CFTR potentiator, VX-770. Proc Natl Acad Sci U S A. 2009; 106:18825-18830. [PubMed: 19846789]

40. Eckford PD, Li C, Ramjeesingh M, Bear CE. Cystic fibrosis transmembrane conductance regulator (CFTR) potentiator VX-770 (ivacaftor) opens the defective channel gate of mutant CFTR in a phosphorylation-dependent but ATP-independent manner. J Biol Chem. 2012; 287:36639-36649. [PubMed: 22942289]

41. Davies JC, Wainwright CE, Canny GJ, Chilvers MA, Howenstine MS, Munck A, Mainz JG, Rodriguez S, Li H, Yen K, et al. Efficacy and safety of ivacaftor in patients aged 6 to 11 years with cystic fibrosis with a G551D mutation. Am J Respir Crit Care Med. 2013; 187:1219-1225. [PubMed: 23590265]

42. Vachel L, Norez C, Becq F, Vandebrouck C. Effect of VX-770 (Ivacaftor) and OAG on Ca(2+) influx and CFTR activity in G551D and F508del-CFTR expressing cells. J Cyst Fibros. 2013; 12:584-591. [PubMed: 23757361]

43. Van Goor F, Yu H, Burton B, Hoffman BJ. Effect of ivacaftor on CFTR forms with missense mutations associated with defects in protein processing or function. J Cyst Fibros. 2013

44. Reznikov LR, Abou Alaiwa MH, Dohrn CL, Gansemer ND, Diekema DJ, Stoltz DA, Welsh MJ. Antibacterial properties of the CFTR potentiator ivacaftor. J Cyst Fibros. 2014

45. Accurso FJ, Rowe SM, Clancy JP, Boyle MP, Dunitz JM, Durie PR, Sagel SD, Hornick DB, Konstan MW, Donaldson SH, et al. Effect of VX-770 in persons with cystic fibrosis and the G551D-CFTR mutation. N Engl J Med. 2010; 363:1991-2003. [PubMed: 21083385]

46. Polenakovik HM, Sanville B. The use of ivacaftor in an adult with severe lung disease due to cystic fibrosis (DeltaF508/G551D). J Cyst Fibros. 2013; 12:530-531. [PubMed: 23313410]

47. Harrison MJ, Murphy DM, Plant BJ. Ivacaftor in a G551D homozygote with cystic fibrosis. N Engl J Med. 2013; 369:1280-1282. [PubMed: 24066763] 
48. Hebestreit H, Sauer-Heilborn A, Fischer R, Kading M, Mainz JG. Effects of ivacaftor on severely ill patients with cystic fibrosis carrying a G551D mutation. J Cyst Fibros. 2013; 12:599-603. [PubMed: 23757359]

49. Barry PJ, Plant BJ, Nair A, Bicknell S, Simmonds NJ, Bell NJ, Shafi NT, Daniels T, Shelmerdine $\mathrm{S}$, Felton I, et al. Effects of ivacaftor in patients with cystic fibrosis who carry the G551D mutation and have severe lung disease. Chest. 2014; 146:152-158. [PubMed: 24522694]

50. Bellin MD, Laguna T, Leschyshyn J, Regelmann W, Dunitz J, Billings J, Moran A. Insulin secretion improves in cystic fibrosis following ivacaftor correction of CFTR: a small pilot study. Pediatr Diabetes. 2013; 14:417-421. [PubMed: 23952705]

51. Hayes D Jr, McCoy KS, Sheikh SI. Resolution of cystic fibrosis-related diabetes with ivacaftor therapy. Am J Respir Crit Care Med. 2014; 190:590-591. [PubMed: 25171312]

52. Ivacaftor. Uncertain harm-benefit balance. Prescrire Int. 2013; 22:229-231. [PubMed: 24298579]

53. McKone EF, Borowitz D, Drevinek P, Griese M, Konstan MW, Wainwright C, Ratjen F, SermetGaudelus I, Plant B, Munck A, et al. Long-term safety and efficacy of ivacaftor in patients with cystic fibrosis who have the Gly551Asp-CFTR mutation: a phase 3, open-label extension study (PERSIST). Lancet Respir Med. 2014

54. KALYDECO (ivacaftor) tablet, film coated [package insert]. Vertex Pharmaceuticals Incorporated, Cambridge, MA 02139. 2012. Permanent link available at: http://dailymed.nlm.nih.gov/dailymed/ lookup.cfm?setid=0ab0c9f8-3eee-4e0f-9f3f-c1e16aaffe25

55. ClinicalTrials.gov identifier. NCT01705145 "Study of Ivacaftor in Cystic Fibrosis Subjects 2 Through 5 Years of Age With a CTFR Gating Mutation". Sponser: Vertex Pharmaceuticals Incorporated; URL: http://clinicaltrials.gov/ct2/show/study/NCT01705145 completed but no study results are posted to date - [accessed 22nd April 2014]

56. ClinicalTrials.gov identifier: NCT01946412. "Roll-Over Study of Ivacaftor in Cystic Fibrosis Pediatric Subjects With a CF Transmembrane Conductance Regulator Gene (CFTR) Gating Mutation”. Sponser: Vertex Pharmaceuticals Incorporated; URL: http://clinicaltrials.gov/ct2/show/ NCT01946412 [enrolling - accessed 22nd April 2014]

57. ClinicalTrials.gov identifier: NCT01614470. "Study of Ivacaftor in Subjects With Cystic Fibrosis Who Have a Non-G551D CFTR Gating Mutation (KONNECTION)”. Sponsor: Vertex Pharmaceuticals Incorporated; URL: http://clinicaltrials.gov/ct2/show/study/NCT01614470 completed but no study results are posted to date - [accessed 23rd Oct 2014]

58. ClinicalTrials.gov Identifier: NCT01614457. "Study of Ivacaftor in Subjects With Cystic Fibrosis Who Have the R117H-CFTR Mutation (KONDUCT)". Sponser: Vertex Pharmaceuticals Incorporated; URL: http://clinicaltrials.gov/ct2/show/study/NCT01614457 completed - no study results posted - [accessed 22nd April 2014]

59. Riordan JR, Rommens JM, Kerem B, Alon N, Rozmahel R, Grzelczak Z, Zielenski J, Lok S, Plavsic N, Chou JL, et al. Identification of the cystic fibrosis gene: cloning and characterization of complementary DNA. Science. 1989; 245:1066-1073. [PubMed: 2475911]

60. NCBI ClinVar database. [Accessed 22nd April 2014] http://www.ncbi.nlm.nih.gov/clinvar/? term=rs 113993960

61. NCBI dbSNP. [Accessed 22nd April 2014] http://www.ncbi.nlm.nih.gov/projects/SNP/ snp_ref.cgi?rs=199826652

62. Welsh MJ, Denning GM, Ostedgaard LS, Anderson MP. Dysfunction of CFTR bearing the delta F508 mutation. J Cell Sci Suppl. 1993; 17:235-239. [PubMed: 7511616]

63. Norman P. Novel picolinamide-based cystic fibrosis transmembrane regulator modulators: evaluation of WO2013038373, WO2013038376, WO2013038381, WO2013038386 and WO2013038390. Expert Opin Ther Pat. 2014

64. Jurkuvenaite A, Chen L, Bartoszewski R, Goldstein R, Bebok Z, Matalon S, Collawn JF. Functional stability of rescued delta F508 cystic fibrosis transmembrane conductance regulator in airway epithelial cells. Am J Respir Cell Mol Biol. 2010; 42:363-372. [PubMed: 19502384]

65. Compain P, Decroocq C, Joosten A, de Sousa J, Rodriguez-Lucena D, Butters TD, Bertrand J, Clement R, Boinot C, Becq F, Norez C. Rescue of functional CFTR channels in cystic fibrosis: a dramatic multivalent effect using iminosugar cluster-based correctors. Chembiochem. 2013; 14:2050-2058. [PubMed: 24038832] 
66. Odolczyk N, Fritsch J, Norez C, Servel N, da Cunha MF, Bitam S, Kupniewska A, Wiszniewski L, Colas J, Tarnowski K, et al. Discovery of novel potent DeltaF508-CFTR correctors that target the nucleotide binding domain. EMBO Mol Med. 2013; 5:1484-1501. [PubMed: 23982976]

67. ClinicalTrials.gov Identifier: NCT01897233. "Study of Lumacaftor in Combination With Ivacaftor in Cystic Fibrosis Subjects 6 to 11 Years of Age With F508del-CFTR Mutation". Sponser: Vertex Pharmaceuticals Incorporated; URL: http://clinicaltrials.gov/ct2/show/NCT01897233? term=ivacaftor\&rank=6 [ongoing - accessed 22nd April 2014]

68. ClinicalTrials.gov Identifier: NCT01807923. “A Study of Lumacaftor in Combination With Ivacaftor in Cystic Fibrosis Subjects Aged 12 Years and Older Who Are Homozygous for the F508del-CFTR Mutation (TRAFFIC)”. Sponser: Vertex Pharmaceuticals Incorporated; URL: http://clinicaltrials.gov/ct2/show/NCT01807923 [ongoing - accessed 22nd April 2014]

69. ClinicalTrials.gov Identifier: NCT01807949. “A Study of Lumacaftor in Combination With Ivacaftor in Cystic Fibrosis Subjects Aged 12 Years and Older Who Are Homozygous for the F508del-CFTR Mutation (TRANSPORT)". Sponser: Vertex Pharmaceuticals Incorporated; URL: http://clinicaltrials.gov/ct2/show/NCT01807949 [ongoing - accessed 22nd April 2014]

70. Van Goor F, Hadida S, Grootenhuis PD, Burton B, Stack JH, Straley KS, Decker CJ, Miller M, McCartney J, Olson ER, et al. Correction of the F508del-CFTR protein processing defect in vitro by the investigational drug VX-809. Proc Natl Acad Sci U S A. 2011; 108:18843-18848. [PubMed: 21976485]

71. He L, Kota P, Aleksandrov AA, Cui L, Jensen T, Dokholyan NV, Riordan JR. Correctors of DeltaF508 CFTR restore global conformational maturation without thermally stabilizing the mutant protein. FASEB J. 2013; 27:536-545. [PubMed: 23104983]

72. Ren HY, Grove DE, De La Rosa O, Houck SA, Sopha P, Van Goor F, Hoffman BJ, Cyr DM. VX-809 corrects folding defects in cystic fibrosis transmembrane conductance regulator protein through action on membrane-spanning domain 1. Mol Biol Cell. 2013; 24:3016-3024. [PubMed: 23924900]

73. Clancy JP, Rowe SM, Accurso FJ, Aitken ML, Amin RS, Ashlock MA, Ballmann M, Boyle MP, Bronsveld I, Campbell PW, et al. Results of a phase IIa study of VX-809, an investigational CFTR corrector compound, in subjects with cystic fibrosis homozygous for the F508del-CFTR mutation. Thorax. 2012; 67:12-18. [PubMed: 21825083]

74. Rowe SM, Verkman AS. Cystic fibrosis transmembrane regulator correctors and potentiators. Cold Spring Harb Perspect Med. 2013:3.

75. Phuan PW, Veit G, Tan J, Roldan A, Finkbeiner WE, G LL, Verkman AS. Synergy-Based SmallMolecule Screen Using a Human Lung Epithelial Cell Line Yields DeltaF508-CFTR Correctors That Augment VX-809 Maximal Efficacy. Mol Pharmacol. 2014; 86:42-51. [PubMed: 24737137]

76. Phuan PW, Yang B, Knapp JM, Wood AB, Lukacs GL, Kurth MJ, Verkman AS. Cyanoquinolines with independent corrector and potentiator activities restore DeltaPhe508-cystic fibrosis transmembrane conductance regulator chloride channel function in cystic fibrosis. Mol Pharmacol. 2011; 80:683-693. [PubMed: 21730204]

77. Flume PA, Liou TG, Borowitz DS, Li H, Yen K, Ordonez CL, Geller DE, Group VXS. Ivacaftor in subjects with cystic fibrosis who are homozygous for the F508del-CFTR mutation. Chest. 2012; 142:718-724. [PubMed: 22383668]

78. Yu W, Kim Chiaw P, Bear CE. Probing conformational rescue induced by a chemical corrector of F508del-cystic fibrosis transmembrane conductance regulator (CFTR) mutant. J Biol Chem. 2011; 286:24714-24725. [PubMed: 21602569]

79. Namkung W, Park J, Seo Y, Verkman AS. Novel amino-carbonitrile-pyrazole identified in a small molecule screen activates wild-type and DeltaF508 cystic fibrosis transmembrane conductance regulator in the absence of a cAMP agonist. Mol Pharmacol. 2013; 84:384-392. [PubMed: 23788656]

80. Kopeikin Z, Yuksek Z, Yang HY, Bompadre SG. Combined effects of VX-770 and VX-809 on several functional abnormalities of F508del-CFTR channels. J Cyst Fibros. 2014

81. Boyle MP, Bell SC, Konstan MW, McColley SA, Rowe SM, Rietschel E, Huang X, Waltz D, Patel NR, Rodman D, group VXs. A CFTR corrector (lumacaftor) and a CFTR potentiator (ivacaftor) for treatment of patients with cystic fibrosis who have a phe508del CFTR mutation: a phase 2 randomised controlled trial. Lancet Respir Med. 2014; 2:527-538. [PubMed: 24973281] 
82. Cholon DM, Quinney NL, Fulcher ML, Esther CR Jr, Das J, Dokholyan NV, Randell SH, Boucher RC, Gentzsch M. Potentiator ivacaftor abrogates pharmacological correction of DeltaF508 CFTR in cystic fibrosis. Sci Transl Med. 2014; 6 246ra296.

83. Veit G, Avramescu RG, Perdomo D, Phuan PW, Bagdany M, Apaja PM, Borot F, Szollosi D, Wu YS, Finkbeiner WE, et al. Some gating potentiators, including VX-770, diminish DeltaF508CFTR functional expression. Sci Transl Med. 2014; 6 246ra297.

84. Xue X, Mutyam V, Tang L, Biswas S, Du M, Jackson LA, Dai Y, Belakhov V, Shalev M, Chen F, et al. Synthetic Aminoglycosides Efficiently Suppress CFTR Nonsense Mutations and are Enhanced by Ivacaftor. Am J Respir Cell Mol Biol. 2013

85. Kerem E, Konstan MW, De Boeck K, Accurso FJ, Sermet-Gaudelus I, Wilschanski M, Elborn JS, Melotti P, Bronsveld I, Fajac I, et al. Ataluren for the treatment of nonsense-mutation cystic fibrosis: a randomised, double-blind, placebo-controlled phase 3 trial. Lancet Respir Med. 2014; 2:539-547. [PubMed: 24836205]

86. McElroy SP, Nomura T, Torrie LS, Warbrick E, Gartner U, Wood G, McLean WH. A lack of premature termination codon read-through efficacy of PTC124 (Ataluren) in a diverse array of reporter assays. PLoS Biol. 2013; 11:e1001593. [PubMed: 23824517]

87. Roberts RG. A read-through drug put through its paces. PLoS Biol. 2013; 11:e1001458. [PubMed: 23824301]

88. Lentini L, Melfi R, Di Leonardo A, Spinello A, Barone G, Pace A, Palumbo Piccionello A, Pibiri I. Toward a rationale for the PTC124 (Ataluren) promoted readthrough of premature stop codons: a computational approach and GFP-reporter cell-based assay. Mol Pharm. 2014; 11:653-664. [PubMed: 24483936]

89. Goodier JL, Mayer J. PTC124 for cystic fibrosis. Lancet. 2009; 373:1426. author reply 1426-1427. [PubMed: 19394530]

90. The Clinical and Functional TRanslation of CFTR (CFTR2). [Accessed 22nd April 2014] available at http://cftr2.org. Specific CFTR2 Mutation List History page: http://www.cftr2.org/ mutations_history.php

91. Phuan PW, Veit G, Tan J, Roldan A, Finkbeiner WE, Lukacs G, Verkman AS. Synergy-based Small-Molecule Screen Using a Human Lung Epithelial Cell Line Yields DeltaF508-CFTR Correctors that Augment VX-809 Maximal Efficacy. Mol Pharmacol. 2014

92. ClinicalTrials.gov. [accessed 22nd April 2014] URL: http://clinicaltrials.gov

93. Yu B, Zhang Y, Sui Y, Yang S, Luan J, Wang X, Ma T, Yang H. Potentiation of mutant CFTR Clchannel currents by the naturally occurring stilbene compound resveratrol. Pharmazie. 2013; 68:877-881. [PubMed: 24380236]

94. Yarlagadda S, Zhang W, Penmatsa H, Ren A, Arora K, Naren AP, Khan FA, Donnellan CA, Srinivasan S, Stokes DC, Kappes JC. A young Hispanic with c.1646G>A mutation exhibits severe cystic fibrosis lung disease: is ivacaftor an option for therapy? Am J Respir Crit Care Med. 2012; 186:694-696. [PubMed: 23027855]

95. McGarry ME, Nielson DW. Normalization of sweat chloride concentration and clinical improvement with ivacaftor in a patient with cystic fibrosis with mutation S549N. Chest. 2013; 144:1376-1378. [PubMed: 24081349] 


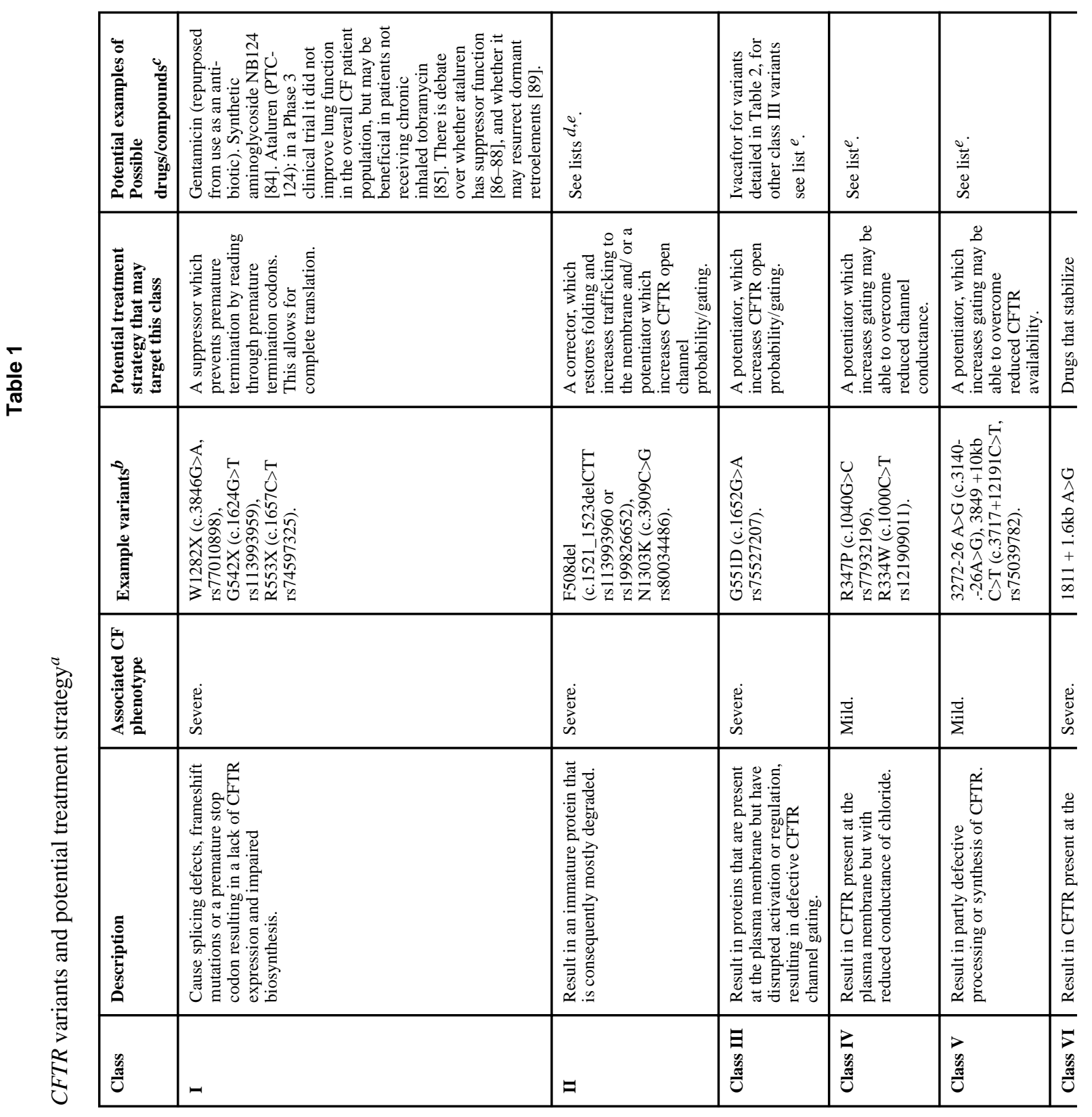

Pharmacogenet Genomics. Author manuscript; available in PMC 2015 March 01. 


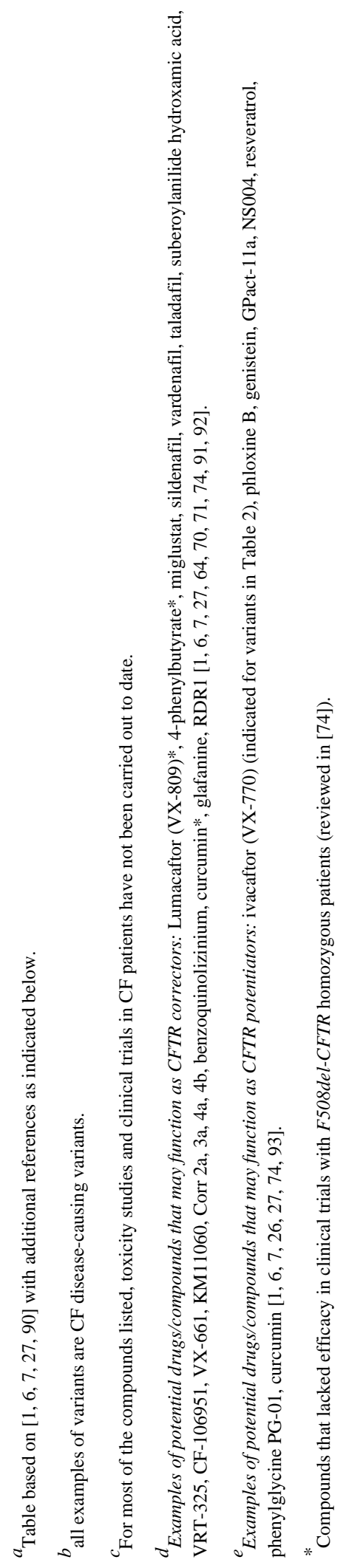

Pharmacogenet Genomics. Author manuscript; available in PMC 2015 March 01. 


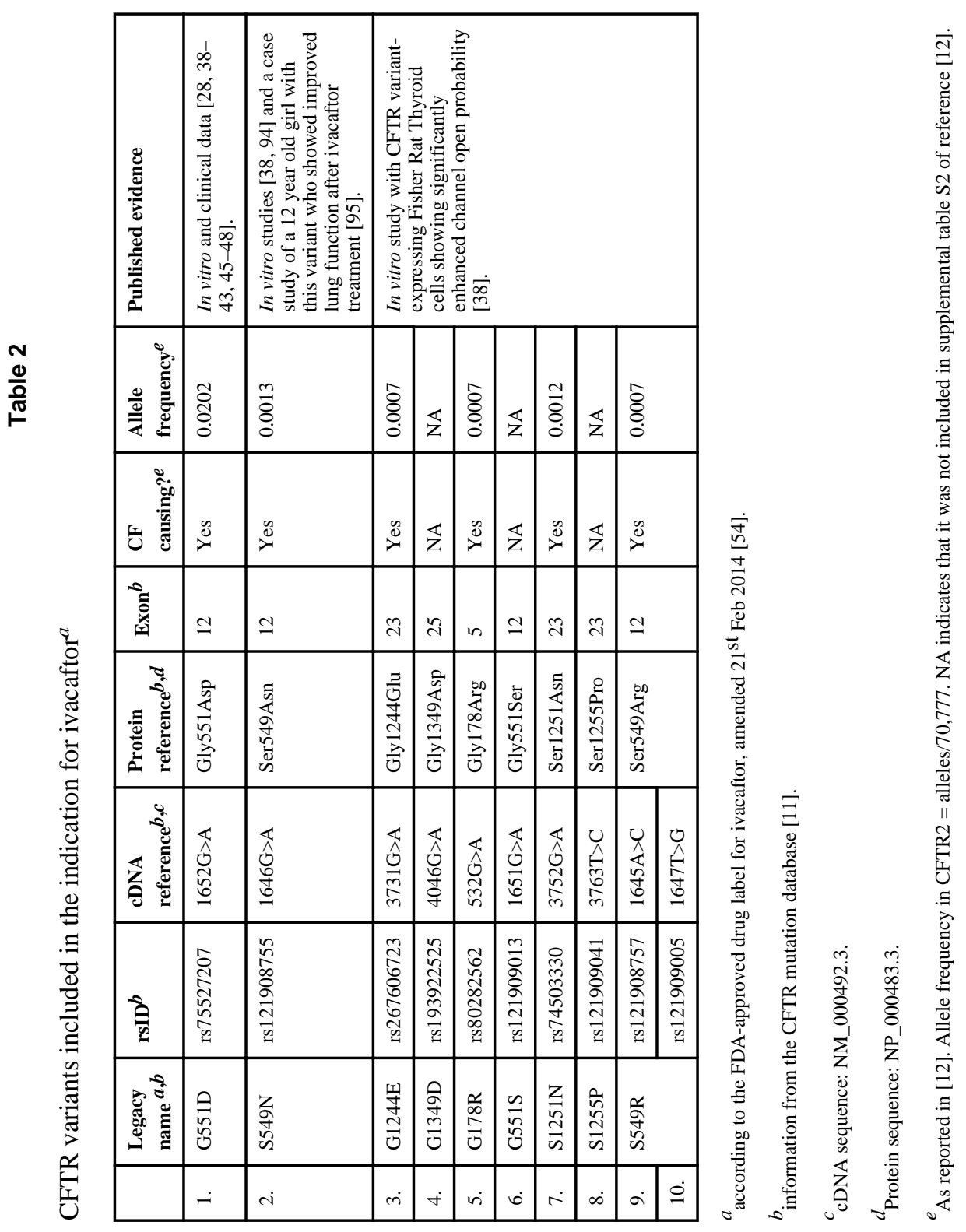

Pharmacogenet Genomics. Author manuscript; available in PMC 2015 March 01. 